\title{
Cyclic Voltammetric Study of High Speed Silver Electrodeposition and Dissolution in Low Cyanide Solutions
}

\author{
Bo Zheng, ${ }^{1,2}$ Lai Peng Wong, ${ }^{2}$ Linda Y. L. Wu, ${ }^{3}$ and Zhong Chen ${ }^{1}$ \\ ${ }^{1}$ School of Materials Science and Engineering, Nanyang Technological University, 50 Nanyang Avenue, Singapore 639798 \\ ${ }^{2}$ MacDermid Enthone, Enthone Chemistry, A Division of Alent Singapore Pte. Ltd., 26 Tuas West Road, Singapore 638382 \\ ${ }^{3}$ Singapore Institute of Manufacturing Technology, 2 Fusionopolis Way, No. 08-04, Innovis, Singapore 138634
}

Correspondence should be addressed to Bo Zheng; bzheng002@ntu.edu.sg and Zhong Chen; aszchen@ntu.edu.sg

Received 7 March 2016; Revised 12 May 2016; Accepted 12 May 2016

Academic Editor: Sheng S. Zhang

Copyright (C) 2016 Bo Zheng et al. This is an open access article distributed under the Creative Commons Attribution License, which permits unrestricted use, distribution, and reproduction in any medium, provided the original work is properly cited.

\begin{abstract}
The electrochemical processes in solutions with a much lower amount of free cyanide $(<10 \mathrm{~g} / \mathrm{L} \mathrm{KCN})$ than the conventional alkaline silver electrolytes were first explored by using cyclic voltammetry. The electrochemical behavior and the effect of $\mathrm{KAg}(\mathrm{CN})_{2}$, $\mathrm{KCN}$, and $\mathrm{KNO}_{3}$ electrolytes and solution $\mathrm{pH}$ on the electrodeposition and dissolution processes were investigated. Moreover, suitable working conditions for high speed, low cyanide silver electrodeposition were also proposed. Both silver and cyanide ions concentration had significant effects on the electrode polarization and deposition rate. The onset potential of silver electrodeposition could be shifted to more positive values by using solutions containing higher silver and lower KCN concentration. Higher silver concentration also led to higher deposition rate. Besides maintaining high conductivity of the solution, $\mathrm{KNO}_{3}$ might help reduce the operating current density required for silver electrodeposition at high silver concentration albeit at the expense of slowing down the electrodeposition rate. The silver dissolution consists of a limiting step and the reaction rate depends on the amount of free cyanide ions. The surface and material characteristics of Ag films deposited by low cyanide solution are also compared with those deposited by conventional high cyanide solution.
\end{abstract}

\section{Introduction}

Silver coatings electrodeposited using cyanide-based solutions have existed for more than one century. Cyanide has played an important role in the silver electrodeposition processes. However, due to stricter rules and regulations, as well as high cost of wastewater treatment, less toxic chemicals have become more favorable in most metal plating processes. Over the years, compounds such as ammonia [1,2], uracil [3], HEDTA [4], 2-hydroxypyridine [5, 6], hydantoin [7], and 5,5dimethylhydantoin $[8,9]$ have been suggested as alternatives to replace cyanides in silver plating baths. In spite of the benefits for using low toxicity cyanide-free silver plating baths, most of these electrolytes have limited practical applications in commercial manufacturing process for reasons such as relatively higher cost, low bath stability, high sensitivity to temperature and metallic contamination, low deposit quality and brightness, and poor adhesion on substrates [3, 10-13].
Hence, the conventional alkaline electrolyte, that is, silver cyanide complex $\left[\operatorname{KAg}(\mathrm{CN})_{2}\right]$ with excess free cyanide (i.e., $\mathrm{NaCN}$ or KCN salt in excess of that required to form silver cyanide complexes), remains one of the most commonly used systems in the electroplating industries to date. Besides being a conducting salt, cyanide is also an excellent complexing agent which complexes not only $\mathrm{Ag}$ ions but also other metallic impurities (especially copper and nickel ions) that are inevitably present in the plating solutions due to the displacement reaction between the substrate and solution ions. Impurities build up over time as $\mathrm{Cu}$ or $\mathrm{Ni}$ dissolves into the plating solution while $\mathrm{Ag}$ precipitates out of the solution. The free cyanide in the solutions will complex with these metallic impurities, thereby ensuring high bath stability and longer bath life. In this way, consistent high quality of $\mathrm{Ag}$ deposit can be obtained.

Furthermore, with the aid of suitable additives such as brighteners and levelers, cyanide-based silver solutions 
also improve the roughness and inhomogeneity of coatings because of their good throwing power, thus producing consistently high quality of white or bright deposits $[14,15]$. Solutions with high throwing power are favorable in the plating process because they ensure uniform deposit on plated parts, especially on those with complex geometries as well as uneven current distribution.

On the other hand, cyanide-free silver plating solutions often make use of the weak chelating agent which only forms weak complexes with the metallic impurities. As a result, poor silver deposits are always formed in aging cyanide-free silver plating solutions as these metallic impurities are codeposited with silver. The weak silver complex formed in cyanide-free silver plating solutions also increased the activity of free Ag ions which facilitates the displacement reactions between substrate and silver ions, releasing more metallic impurities into the plating solutions.

As a consequence, manufacturers still tend to stay with cyanide-based solutions due to their high bath stability, ease of operation, and consistently high quality of silver coatings. Implementing cyanide-free plating solutions in manufacturing industries remains a great challenge [9].

Electrodeposited silver has been playing important roles in decorative applications and electronics industries for decades. In response to the high demands in advanced electronics products, good quality silver plating at high speed has become a critical step in the manufacturing process. Moreover, new applications in electronics and semiconductor industries have also encouraged the development of new silver chemistries for high speed selective plating, such as mirror bright silver spot plating on leadframes.

Similar to conventional alkaline silver electrolytes, high speed silver plating solutions usually have high potassium cyanide content (45-100 g/L) and are not suitable for selective or spot plating [16]. In high speed silver spot plating on leadframes, the leadframes are plated with silver to give a bondable area on the lead finger to allow a second bond to form subsequently. This area must be slightly larger than the size of the second bond. Insoluble anodes such as platinised titanium mesh or platinum wire are commonly used as only the tip of the lead finger is plated for bonding [17]. Oxidation and polymerization of cyanide [18] at these insoluble anodes have caused rapid degradation of the high cyanide silver plating solutions.

Hence, it would be desirable if the negative effect of cyanide is minimized while at the same time the high quality of silver coatings could be maintained consistently. Besides that, because of the low cyanide content, the accumulation of carbonates could be slowed down. As a consequence, the low cyanide silver bath life could also be extended.

In this work, the silver electrochemical processes in solutions consisting of a much lower amount of free cyanide $(<10 \mathrm{~g} / \mathrm{L} \mathrm{KCN})$ than the conventional alkaline silver electrolytes were first explored by using cyclic voltammetric technique. The electrochemical behaviors and effects of the basic electrolytes (silver salt, potassium cyanide, and conducting salt) and solution $\mathrm{pH}$ on the electrodeposition and dissolution processes were also investigated. In addition, the optimum working conditions for high speed silver electrodeposition in low cyanide system were also proposed.

In order to ensure the feasibility of replacing high cyanide with low cyanide system in practical applications, the characteristics such as morphologies, purity, brightness, conductivity, and hardness of Ag films electrodeposited by low cyanide system will also be compared with those electrodeposited by conventional high cyanide silver solution.

\section{Materials and Methods}

2.1. Chemicals and Plating Conditions. Chemicals used were potassium silver (I) cyanide $\left(\mathrm{KAg}(\mathrm{CN})_{2}\right)$, potassium nitrate $\left(\mathrm{KNO}_{3}\right)$, potassium cyanide $(\mathrm{KCN})$, nitric acid $\left(\mathrm{HNO}_{3}\right)$, and potassium hydroxide $(\mathrm{KOH})$. All solutions were prepared with deionized water. The $\mathrm{pH}$ of the solution was adjusted by using either $1 \% \mathrm{HNO}_{3}$ or $1 \% \mathrm{KOH}$ solutions.

Brass hull cell panel was used as a substrate for silver electrodeposition. All the pretreatment $\mathrm{Ni}$ and Ag electrodeposition chemicals used are proprietary products provided by MacDermid Enthone. Before deposition, the brass was cleaned in the Enprep 110 EC, Enprep 220 EC, and Actane 345. After that, the brass was electrodeposited with a layer of nickel $(2-3 \mu \mathrm{m})$ by using Heliofab Ni-370. Next, a thin layer of Ag was electrodeposited on the $\mathrm{Ni} /$ brass panel by using two types of silver solutions, that is, low cyanide silver solution and conventional high cyanide silver solution. The low cyanide silver solution was made up of $120 \mathrm{~g} / \mathrm{L} \operatorname{KAg}(\mathrm{CN})_{2}$, $6 \mathrm{~g} / \mathrm{L} \mathrm{KCN}, 120 \mathrm{~g} / \mathrm{L} \mathrm{KNO}_{3}, 5 \mathrm{~mL} / \mathrm{L}$ XRD Ag-7000 B1, and $16 \mathrm{~mL} / \mathrm{L}$ XRD Ag-7000 B2, while the high cyanide silver solution consisted of $100 \mathrm{~g} / \mathrm{L} \mathrm{KAg}(\mathrm{CN})_{2}, 150 \mathrm{~g} / \mathrm{L} \mathrm{KCN,} 6 \mathrm{~g} / \mathrm{L}$ $\mathrm{KOH}, 20 \mathrm{~g} / \mathrm{L} \mathrm{K}_{2} \mathrm{CO}_{3}, 5 \mathrm{~mL} / \mathrm{L}$ Heliofab Ag-900 C and T, and $3 \mathrm{~mL} / \mathrm{L}$ Heliofab Ag-900 H. The electrodeposition conditions followed the optimum parameters as recommended in the XRD Ag-7000 and Heliofab Ag-900 technical datasheets. The $\mathrm{pH}$ values of the freshly prepared silver solutions were adjusted to about 10-12 for both low and conventional high cyanide solutions.

The current densities used for the electrodeposition are $0.6 \mathrm{~A} / \mathrm{cm}^{2}$ for low cyanide system and $0.03 \mathrm{~A} / \mathrm{cm}^{2}$ for conventional high cyanide system. The deposition time of the two systems was adjusted so that the Ag films had a similar thickness at 2.0-2.5 $\mu \mathrm{m}$.

2.2. Cyclic Voltammetric Analysis. The electrochemical studies of silver electrodeposition and dissolution were performed in a conventional three-electrode cell using computerized potentiostat (797 VA Computrace, Metrohm) at room temperature. Polished platinum rotating disk (Metrohm, $A=$ $0.0314 \mathrm{~cm}^{2}$ ) was used as the working electrode. During the experiments, $\mathrm{Ag} / \mathrm{AgCl}(3 \mathrm{M} \mathrm{KCl})$ reference electrode was mounted in an electrolyte vessel filled with $1 \mathrm{M} \mathrm{KNO}_{3}$ solution and used as a double junction reference electrode. All the potential measured in the voltammetric study referred to this reference electrode. A platinum rod which represented the insoluble anode in industrial practice was employed as the counter electrode. All the silver electrodeposition and dissolution processes were studied at angular speed $(\omega)$ of $1200 \mathrm{rpm}$. The cyclic voltammetry scan rate was $50 \mathrm{mVs}^{-1}$. 
Before each measurement, the electrode was cleaned in deionized water, followed by $50 \% \mathrm{HNO}_{3}$ solution and $10 \%$ $\mathrm{KOH}$ solution, and rinsed with deionized water. After that, the electrode was sonicated in deionized water for $5 \mathrm{~min}$ before use.

2.3. Ag Films Characterization. The surface morphology of the Ag films was observed under scanning electron microscope (SEM, JSM-6360A, JEOL) while their surface roughness was measured using atomic force microscope (AFM, DI3100, Digital Instruments). Furthermore, X-ray diffraction (XRD) analysis was also performed for characterizing the crystal orientation of the surfaces of electrodeposited Ag films. Thin Film XRD (XRD-6000, Shimadzu) with $\mathrm{Cu} \mathrm{K}_{\alpha}$ radiation $(40 \mathrm{kV}, 30 \mathrm{~mA})$ was used. The samples were scanned continuously at $2^{\circ} 2 \theta \mathrm{min}^{-1}$. The compositional profile of the silver films was investigated by X-ray photoelectron spectroscopy (Thermo Scientific, ESCALAB 250Xi). The samples were scanned by $\mathrm{Al} \mathrm{K}_{\alpha}(1486.6 \mathrm{eV})$ radiation.

The brightness or reflectance of the Ag films was determined by using a spectroscopic reflectometer (RadiTech) at a light incidence angle of $0^{\circ}$. Silicon-based wafer was used as the reference and the intensity change of light reflected from the surface of Ag samples was measured as a function of wavelength $(\lambda=450 \mathrm{~nm})$ at normal incidence. Reflectance readings were taken at $\lambda=450 \mathrm{~nm}$ (blue light) because this wavelength is more critical in the LED application. A fourpoint probe (CMT-SR2000N, AIT) was used to measure the resistivity of the Ag samples. The hardness of the Ag layer was measured by Micro Hardness Tester (Shimadzu HMV2) with a $50 \mathrm{~g}$ load.

\section{Results and Discussion}

3.1. Cyclic Voltammetry of $\mathrm{Ag} / \mathrm{Ag}^{+}$at Rotating Disk Platinum Electrode. The voltammetric studies of $\mathrm{KAg}(\mathrm{CN})_{2}, \mathrm{KNO}_{3}$, and $\mathrm{KCN}$ electrolytes and solutions $\mathrm{pH}$ were performed over the platinum rotating disk electrode in order to analyze the different redox processes and to determine the suitable working potential range for silver electrodeposition. Rotating disk electrode was used in the experiments because it gave agitation to the solution which could reduce the thickness and prevent the impoverishment of diffusion layer lying between the bulk solution and the working electrode surface, thereby ensuring uniform deposition.

Figure 1(a) shows the redox reactions of $120 \mathrm{~g} / \mathrm{L}$ $\mathrm{KAg}(\mathrm{CN})_{2}$ in the absence or presence of $\mathrm{KNO}_{3}$ and $\mathrm{KCN}$. During the 1st scan cycle of $120 \mathrm{~g} / \mathrm{L} \mathrm{KAg}(\mathrm{CN})_{2}$, it is observed that a drastic increase in the cathodic current appears at $\sim-0.41 \mathrm{~V}$ (Figure 1(a), peak C1) and an anodic reaction occurs at $\sim-2 \mathrm{mV}$ (Figure 1(a), peak A1), corresponding to the silver electrodeposition and silver film dissolution, respectively. An additional cathodic peak $\mathrm{C} 2$ became pronounced around $-50 \mathrm{mV}$ during the $2 \mathrm{nd}$ scan cycle (Figure 1(b)). This may be due to the incomplete silver dissolution during the first anodic scan, giving rise to the presence of oxidized and nondissolved silver film on the platinum surface from the beginning of the next scan [19].
In contrast to the onset potential of silver electrodeposition at the 1st scan cycle, the reduction of silver ions starts at a more positive potential from the 2 nd scan cycle onwards, which is at $-280 \mathrm{mV}$. As platinum working electrode (which is different from the deposited metal) is employed, the initiation of nucleation normally consumes more energy to produce the first nucleus [20]. Besides that, the presence of nondissolved silver film on the electrode may also facilitate the nucleation and growth processes during the 2nd scan cycle.

The addition of supporting electrolyte $\mathrm{KNO}_{3}$ to $120 \mathrm{~g} / \mathrm{L}$ $\mathrm{KAg}(\mathrm{CN})_{2}$ solution has significantly lowered the cathodic current density of silver reduction as a steady-state limiting current is achieved when compared to that that occurs in the $\mathrm{KAg}(\mathrm{CN})_{2}$ solution without supporting electrolyte. This is because the migration effect of silver ions is minimized in the presence of supporting electrolyte.

It is clear that, in the presence of $\mathrm{KCN}$, the onset potential of silver electrodeposition is shifted to more negative values (Figure 1(a), peak C3) while the silver dissolution wave (peak A2) becomes broader and the anodic current density reaches a plateau before it drops abruptly. When the vertex potential of cathodic scan is raised to more negative values, the amount of silver deposited is enhanced as depicted by the increase in the dissolution wave areas in Figure 1(c). The cyclic voltammogram also shows a characteristic hysteresis which appears after potential sweep reversal. This is the characteristic of metal nucleation or growth on working electrode [21]. In addition, steady-state limiting current of silver electrodeposition is achieved around $-0.83 \mathrm{~V}$ and the proton reduction or hydrogen evolution is noticed to occur beyond $\sim-0.86 \mathrm{~V}$. Any deposition carried out beyond these negative potentials might produce silver film with pitting and adhesion defects $[13,22]$. As a result, the silver electrodeposition process will only be examined below $-0.8 \mathrm{~V}$ in this study.

Assuming that only $\mathrm{Ag}(\mathrm{CN})_{2}{ }^{-}$complexes exist in the solutions and all silver atoms come from this complex, the charge transfer of silver electrodeposition in Figure 1(a), peaks $\mathrm{C} 1$ and $\mathrm{C} 3$, can be described by (1). The difference in the free cyanide concentration in the solution has induced the change in the onset potential of electrodeposition. On the contrary, the dissolution of Ag (peak A2) can also be represented by the reverse reaction of

$$
\mathrm{Ag}(\mathrm{CN})_{2}{ }^{-}+\mathrm{e}^{-} \leftrightarrows \mathrm{Ag}+2 \mathrm{CN}^{-}
$$

However, several chemical steps such as the dissociation of cyanide ions, reduction of silver ions, and removal of cyanide ions from the electrode/electrolyte interface may take place simultaneously as well. Another situation that involves the partial or complete dissociation of $\mathrm{Ag}(\mathrm{CN})_{2}{ }^{-}$ anion is shown in (2)-(5) [23]. The cathodic peak C2 shown in Figure 1(b) corresponds to (5) where the reduction of nondissolved Ag film occurs. Hence,

$$
\begin{aligned}
\mathrm{Ag}(\mathrm{CN})_{2}{ }^{-} & \leftrightarrows \mathrm{AgCN}+\mathrm{CN}^{-} \\
\mathrm{AgCN} & \leftrightarrows \mathrm{Ag}^{+}+\mathrm{CN}^{-} \\
\mathrm{Ag}^{+}+\mathrm{e}^{-} & \leftrightarrows \mathrm{Ag} \\
\mathrm{AgCN}+\mathrm{e}^{-} & \leftrightarrows \mathrm{Ag}+\mathrm{CN}^{-}
\end{aligned}
$$




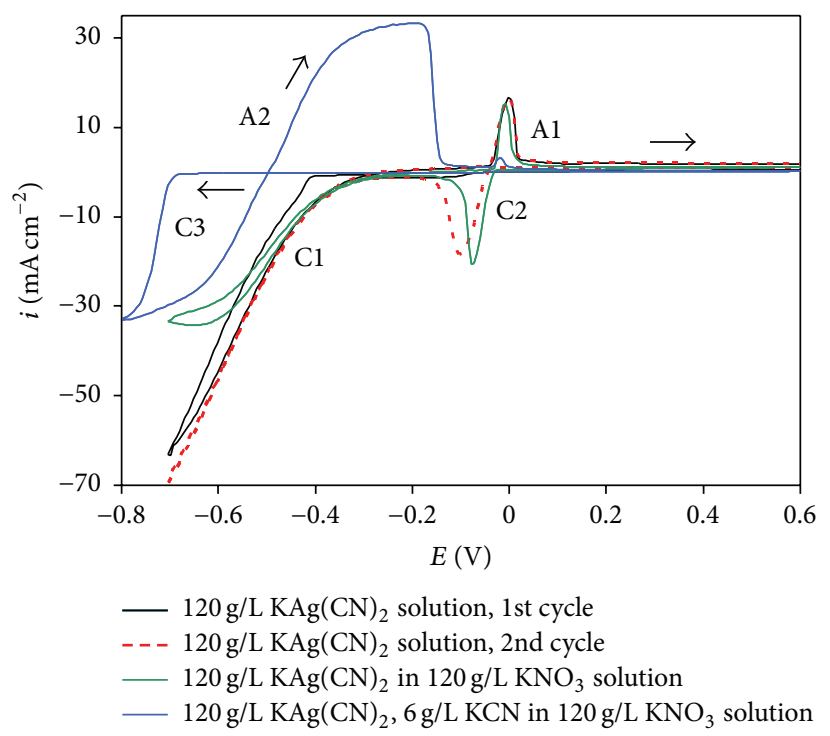

(a)

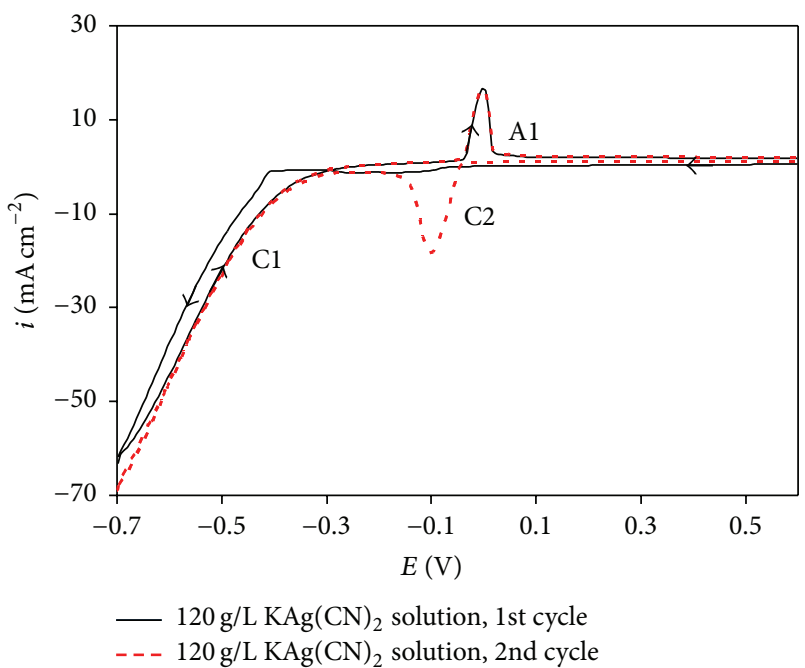

(b)

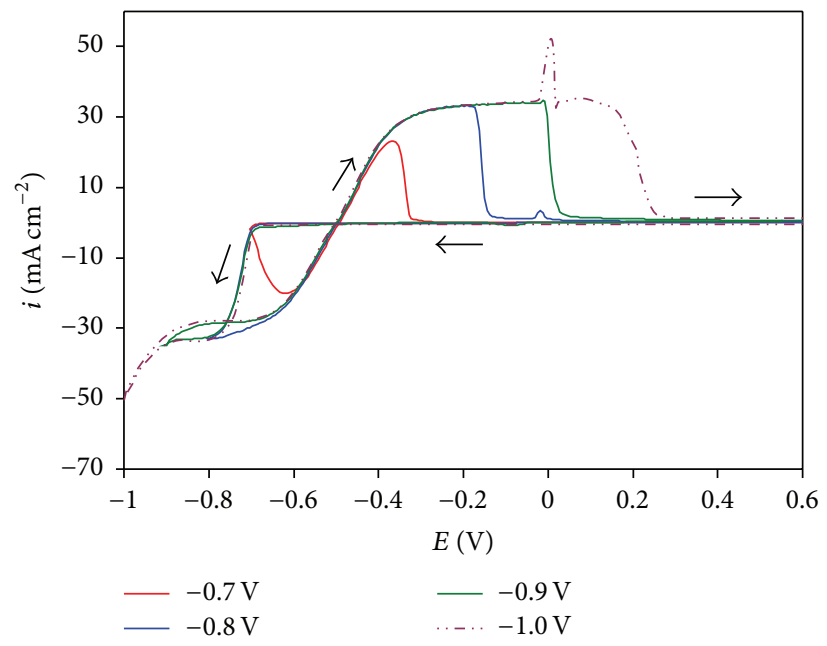

(c)

FIGURE 1: Cyclic voltammograms of (a) silver electrodeposition and silver dissolution in the absence and presence of $\mathrm{KNO}_{3}$ and $\mathrm{KCN}$; (b) $120 \mathrm{~g} / \mathrm{L} \mathrm{KAg}(\mathrm{CN})_{2}$ only; (c) the influence of cathodic vertex potential in $120 \mathrm{~g} / \mathrm{L} \mathrm{KAg}(\mathrm{CN})_{2}, 6 \mathrm{~g} / \mathrm{L} \mathrm{KCN}$, and $120 \mathrm{~g} / \mathrm{L} \mathrm{KNO}_{3}$ solutions. Arrows show the potential sweep direction. Initial potential $=+0.6 \mathrm{~V}$. Sweep rate: $50 \mathrm{mVs}^{-1}$. C1, C2, and C3 denote the cathodic peaks while A1 and A2 correspond to the anodic peaks.

In fact, the silver electrodeposition process in cyanide system involves more complicated mechanisms because of the formation of more than one silver complex, that is, $\mathrm{AgCN}, \mathrm{Ag}(\mathrm{CN})_{2}{ }^{-}, \mathrm{Ag}(\mathrm{CN})_{3}{ }^{2-}$, and $\mathrm{Ag}(\mathrm{CN})_{4}{ }^{3-}$, in which equilibrium concentration and the predominant species that take part in the charge transfer process rely on the cyanide concentration in the solutions [24]. When the free cyanide is insufficient, the dissolution of Ag (Figure 1(b), peak A1) may proceed in the reverse direction of (5).

3.2. The Effect of $\mathrm{KAg}(\mathrm{CN})_{2}$ Concentration on the Electrodeposition of Silver. Figure 2(a) shows the effect of $\mathrm{KAg}(\mathrm{CN})_{2}$ concentration on the silver electrodeposition as well as silver dissolution. When the amount of $\operatorname{KAg}(\mathrm{CN})_{2}$ is increased from 60 to $200 \mathrm{~g} / \mathrm{L}$ in the solutions containing $6 \mathrm{~g} / \mathrm{L} \mathrm{KCN}$, the onset potentials of silver electrodeposition are shifted towards more positive values (Figure 2(b)). In other words, as the source of silver increases, the cathodic polarization is lowered. When the amount of $\mathrm{KCN}$ remains constant, increasing $\mathrm{KAg}(\mathrm{CN})_{2}$ concentration will increase the number of silver cyanide complex ions as well as the silver cations in the solution, thus lowering the cyanide coordination number of silver complex, enabling the deposition to proceed more easily.

Moreover, higher $\mathrm{KAg}(\mathrm{CN})_{2}$ concentration enables higher current densities as well as larger amount of silver deposited, resulting in higher electrodeposition rate (Figure 2(c)). This also implies that a large amount of silver salt 


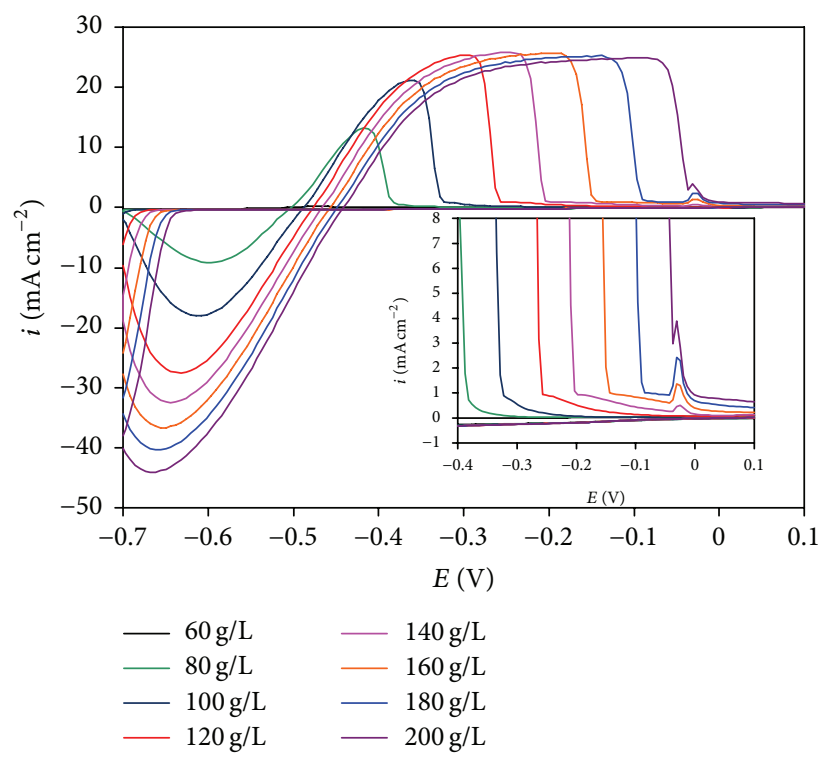

(a)
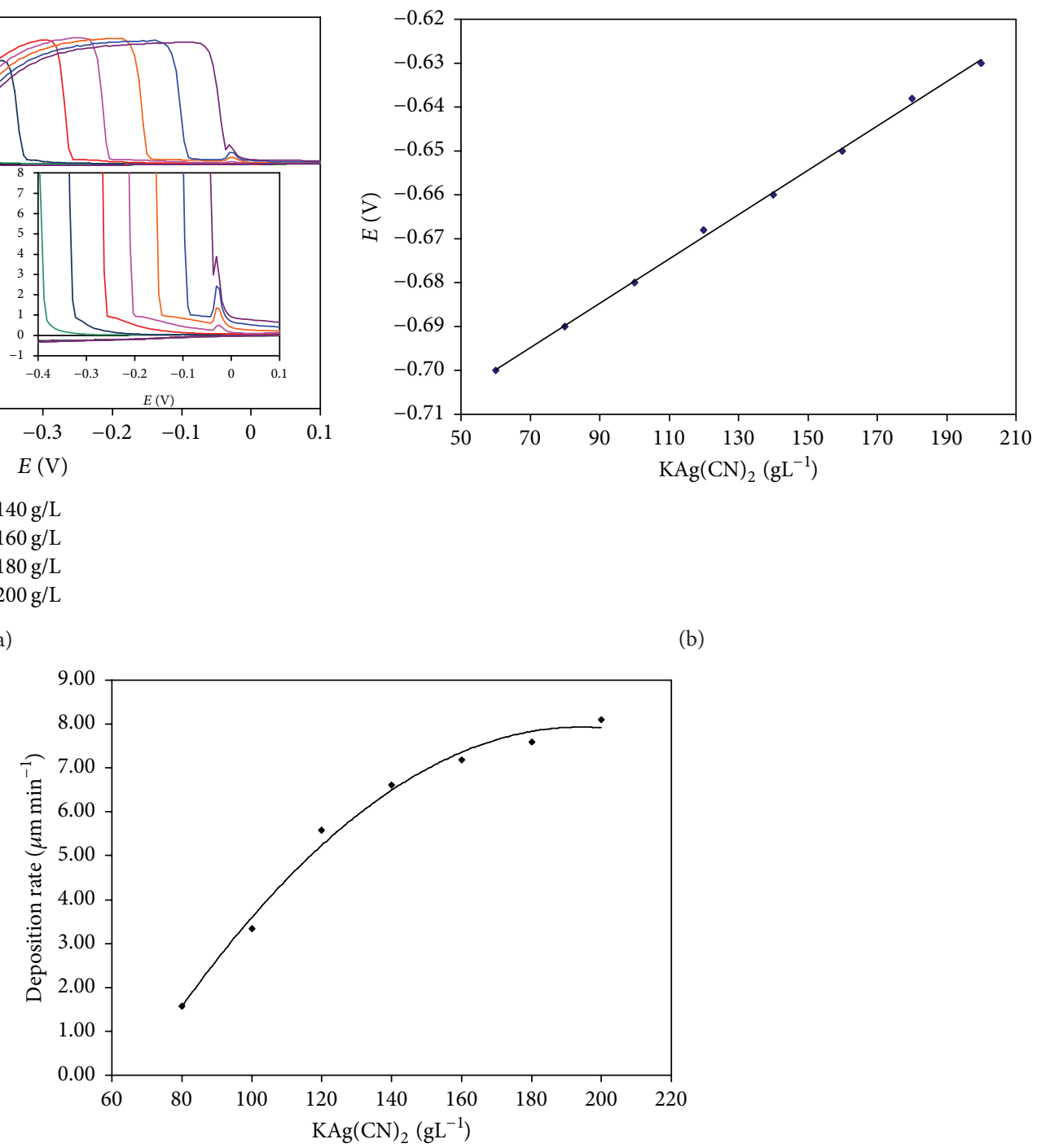

(c)

FIgURE 2: (a) Cyclic voltammograms of silver electrodeposition and silver dissolution in the solutions consisting of $6 \mathrm{~g} / \mathrm{L} \mathrm{KCN} 120 \mathrm{~g} / \mathrm{L} \mathrm{KNO}_{3}$, and 60-200 g/L KAg $(\mathrm{CN})_{2}$. Inset: the current response of second anodic peak increases with increasing $\mathrm{KAg}(\mathrm{CN})_{2}$ concentration during the anodic scan. (b) The effect of $\mathrm{KAg}(\mathrm{CN})_{2}$ concentration on the onset potential of silver electrodeposition. (c) The influence of $\mathrm{KAg}(\mathrm{CN})_{2}$ concentration on the electrodeposition rate in the sweeping potential range from $+0.6 \mathrm{~V}$ to $-0.7 \mathrm{~V}$.

is critical for high speed silver plating. Deposition rate is determined by

$$
\text { Deposition rate }=\frac{Q M_{\mathrm{Ag}}}{F \rho_{\mathrm{Ag}} A t} \times 10^{4}(\mu \mathrm{m} / \mathrm{min}),
$$

where $Q(C)$ is the charge involved in the silver dissolution; $M_{\mathrm{Ag}}(=107.8682 \mathrm{~g} / \mathrm{mol})$ is the molar mass of silver; $F$ (= $96485.3365 \mathrm{C} / \mathrm{mol})$ is the Faraday Constant; $\rho_{\mathrm{Ag}}(=10.49 \mathrm{~g} /$ $\left.\mathrm{cm}^{3}\right)$ is the density of silver; $A\left(=0.0314 \mathrm{~cm}^{2}\right)$ is the Pt electrode area; $t(\mathrm{~min})$ is the deposition time during the cathodic sweep.

It is observed that one main silver dissolution wave and one shoulder peak appear during the anodic scan (Figure $2(\mathrm{a}))$. At low cyanide $(6 \mathrm{~g} / \mathrm{L} \mathrm{KCN})$ and high $\mathrm{KAg}(\mathrm{CN})_{2}$
(>120 g/L) concentration, the dissolution waves of silver cover a broad potential range and achieve a steady-state limiting current. This may be due to the rate limiting steps which are involved in the cyanidation of dissolved silver.

On the other hand, the splitting of the dissolution wave can be due to the formation of different silver complex in the solutions. Increase in the $\operatorname{KAg}(\mathrm{CN})_{2}$ concentration has also raised the anodic peak current at $\sim-31 \mathrm{mV}$ (Figure 2(a), inset). This shoulder peak is attributed to the formation of $\mathrm{AgCN}$ as the concentration of free cyanide available in the solution is insufficient to form soluble silver complex. This is even more noticeable when the amount of deposited $\mathrm{Ag}$ increased with increasing $\mathrm{KAg}(\mathrm{CN})_{2}$ concentration while the free cyanide concentration remains constant. 
3.3. The Effect of KCN Concentration on the Electrodeposition of Silver. It has been shown in Figure 1 that, in the presence of $\mathrm{KCN}$, both silver electrodeposition and silver film dissolution reactions are clearly shifted towards more negative potentials. Depending on the cyanide concentration in the solution, the coordination number of silver cyanide complexes and the predominant complex ions will change accordingly following (7)-(10) [25]. The species that are involved in the charge transfer process rely not only on the cyanide concentration, but also on the operating conditions. Previous studies [26, 27] had reported that it was the $\mathrm{AgCN}$ that is involved in the charge transfer when free cyanide $\left[\mathrm{CN}^{-}\right]$was in the concentration range of less than $0.1 \mathrm{M}(2.6 \mathrm{~g} / \mathrm{L})$, whereas $\mathrm{Ag}(\mathrm{CN})_{2}{ }^{-}$complex took part in the charge transfer step when $\left[\mathrm{CN}^{-}\right]>0.2 \mathrm{M}(5.2 \mathrm{~g} / \mathrm{L})$. At high cyanide concentration, $\left[\mathrm{CN}^{-}\right]>0.9 \mathrm{M}(23.4 \mathrm{~g} / \mathrm{L}), \mathrm{Ag}(\mathrm{CN})_{3}{ }^{2-}$ complex was suggested to be the species that is involved in the charge transfer process. On the other hand, the impedance study by Baltrunas [28] had shown that $\operatorname{Ag}(\mathrm{CN})_{2}{ }^{-}$complex is always involved in the direct charge transfer step regardless of the cyanide concentration and the composition of the solutions. Hence,

$$
\begin{gathered}
\mathrm{Ag}^{+}+\mathrm{CN}^{-} \leftrightarrows \mathrm{AgCN} \\
\mathrm{Ag}^{+}+2 \mathrm{CN}^{-} \leftrightarrows \mathrm{Ag}(\mathrm{CN})_{2}{ }^{-} \\
\mathrm{Ag}(\mathrm{CN})_{2}{ }^{-}+\mathrm{CN}^{-} \leftrightarrows \mathrm{Ag}(\mathrm{CN})_{3}{ }^{2-} \\
\mathrm{Ag}(\mathrm{CN})_{3}{ }^{2-}+\mathrm{CN}^{-} \leftrightarrows \mathrm{Ag}(\mathrm{CN})_{4}{ }^{3-}
\end{gathered}
$$

Generally, due to the strong complex-forming effect between the cyanide ions and silver ions, the cyanide ions will shift the equilibrium potential to more negative values and increase the activation polarization by reducing the activity as well as the concentration of the free $\mathrm{Ag}^{+}$ions [14]. As a result, in contrast to the effect of increasing the $\operatorname{KAg}(\mathrm{CN})_{2}$ concentration, the higher the KCN concentration, the more negative the potential required to deposit silver coating on platinum electrode (Figure 3). The difference in the onset potential of silver electrodeposition between the solutions containing $6 \mathrm{~g} / \mathrm{L} \mathrm{KCN}$ and $0 \mathrm{~g} / \mathrm{L} \mathrm{KCN}$ was about $-0.38 \mathrm{~V}$. Unlike cyanide-free silver electrolytes, cyanide-based silver electrolytes with the addition of suitable brighteners always produce white and bright silver deposits. This is because the increase in the cathodic polarization helped promote the growth of fine-grained deposits [14].

High level of free cyanide is necessary in order to maintain consistent and high quality of silver coatings in industrial practice. However, in the case of high speed selective plating where insoluble anodes are commonly employed, the silver plating solution should contain only as much free cyanide as necessary so that the formation of insoluble AgCN [29] at the anodes, which will impede the current flow, can be avoided.

According to Figure 3, less than about $45 \mathrm{~g} / \mathrm{L} \mathrm{KCN} \mathrm{in} \mathrm{a}$ solution consisting of $120 \mathrm{~g} / \mathrm{L} \mathrm{KAg}(\mathrm{CN})_{2}$ and $120 \mathrm{~g} / \mathrm{L} \mathrm{KNO}_{3}$ will ensure that the potential required to initiate the silver electrodeposition will not occur in parallel with the hydrogen evolution reaction. Since it is critical that only very low and necessary amount of KCN should be used in developing the new silver plating chemistry, $4-8 \mathrm{~g} / \mathrm{L} \mathrm{KCN}$ in the low

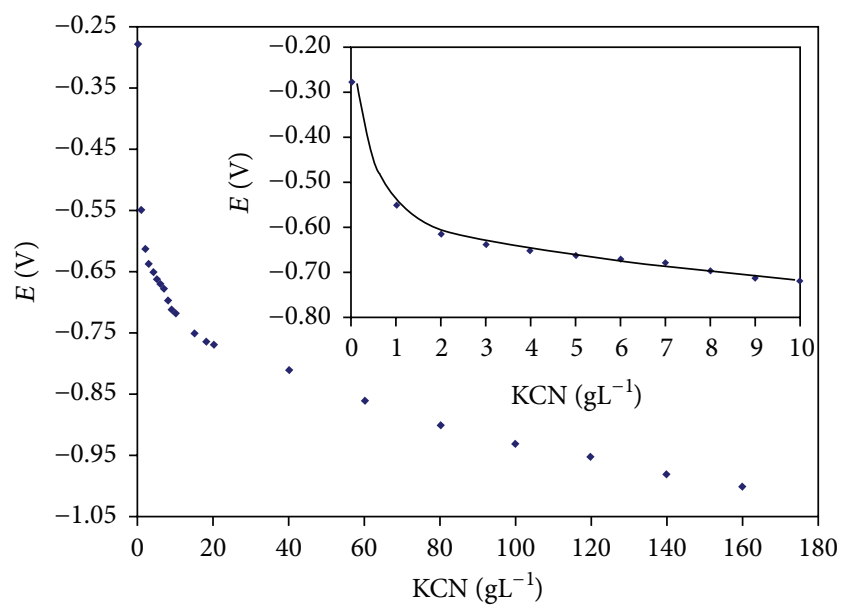

FIGURE 3: The effect of KCN concentration on the onset potential of silver electrodeposition. The silver plating solution consists of $120 \mathrm{~g} / \mathrm{L} \mathrm{KAg}(\mathrm{CN})_{2}, 120 \mathrm{~g} / \mathrm{L} \mathrm{KNO}_{3}$, and $0-160 \mathrm{~g} / \mathrm{L} \mathrm{KCN}$. Inset: the onset potential of silver electrodeposition in the range of $0-10 \mathrm{~g} / \mathrm{L}$ $\mathrm{KCN}$.

cyanide region $(<10 \mathrm{~g} / \mathrm{L})$ is found to be suitable under the existing given $\mathrm{KAg}(\mathrm{CN})_{2}$ and $\mathrm{KNO}_{3}$ concentrations because a slight drop or increase in the KCN concentration will not significantly affect the polarization of the working electrode and thereby the plating solutions will be easier to control during operation.

3.4. The Effect of $\mathrm{KNO}_{3}$ Concentration on the Electrodeposition of Silver. As mentioned previously, addition of supporting electrolyte $\mathrm{KNO}_{3}$ to the solution containing $120 \mathrm{~g} / \mathrm{L}$ $\mathrm{KAg}(\mathrm{CN})_{2}$ has lowered the cathodic current density significantly. The same behavior is also observed in the solution consisting of $120 \mathrm{~g} / \mathrm{L} \mathrm{KAg}(\mathrm{CN})_{2}$ and $6 \mathrm{~g} / \mathrm{L} \mathrm{KCN}$ in Figure 4(a). The higher the $\mathrm{KNO}_{3}$ concentration, the lower the cathodic current density and as a consequence lesser silver is deposited on Pt electrode. The decrease in the dissolution peak areas with increasing $\mathrm{KNO}_{3}$ concentration has also suggested that $\mathrm{KNO}_{3}$ can be used to adjust the rate of electrodeposition process at constant applied potential, as shown in Figure 4(b).

The cathodic current density in the absence or at a low concentration of $\mathrm{KNO}_{3}$ is obviously larger than that at higher concentration because the migration of the $\mathrm{Ag}^{+}$towards the working electrode during the cathodic scan has enhanced the faradaic current. At high concentration of $\mathrm{KNO}_{3}, \mathrm{~K}^{+}$ migration replaces that of $\mathrm{Ag}^{+}$and thus the observed faradaic current is mainly contributed by the diffusion current [30]. In this way, $\mathrm{KNO}_{3}$ can improve the conductivity of the solution and it can also be used to control the deposition rate if required during application.

On the other hand, unlike $\mathrm{KAg}(\mathrm{CN})_{2}$ and $\mathrm{KCN}, \mathrm{KNO}_{3}$ does not alter the onset potential of electrodeposition process significantly. Moreover, in contrast with the influence of $\mathrm{KNO}_{3}$ on the current density of silver electrodeposition, increasing $\mathrm{KAg}(\mathrm{CN})_{2}$ concentration has the opposite effect in which the current density increases with increasing silver ion concentration at constant potential. In other words, adding 


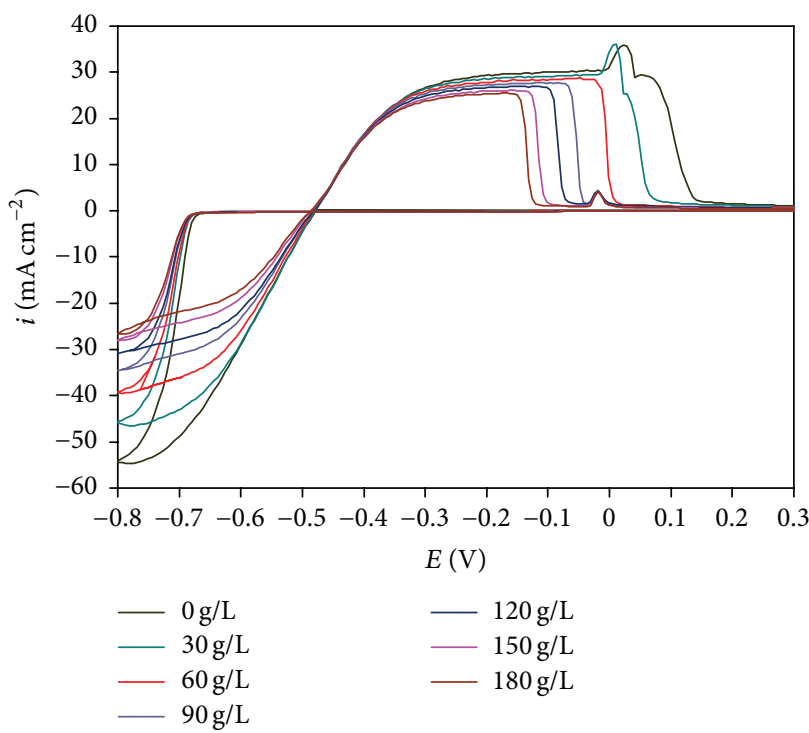

(a)

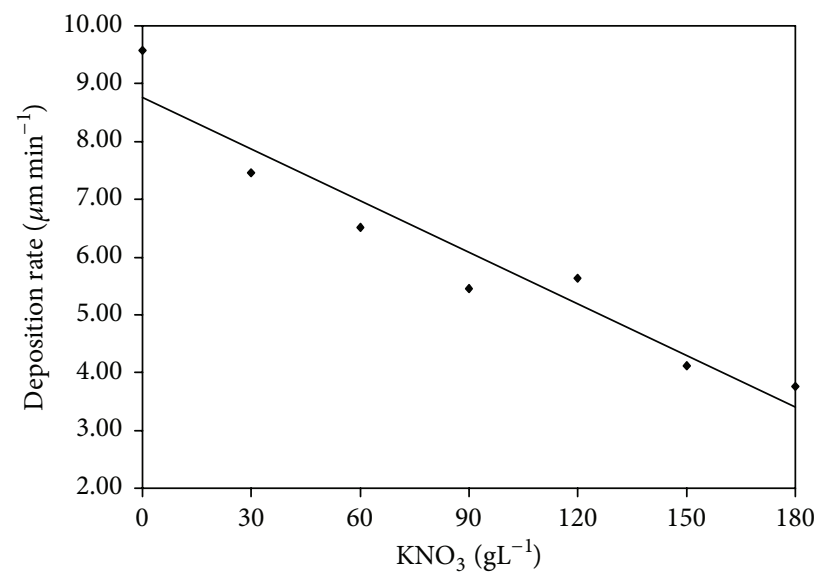

(b)

Figure 4: (a) Cyclic voltammograms of silver electrodeposition and silver film dissolution in the silver plating solution consisting of $120 \mathrm{~g} / \mathrm{L}$ $\mathrm{KAg}(\mathrm{CN})_{2}, 6 \mathrm{~g} / \mathrm{L} \mathrm{KCN}$, and $0-180 \mathrm{~g} / \mathrm{L} \mathrm{KNO}_{3}$. (b) The effect of $0-180 \mathrm{~g} / \mathrm{L} \mathrm{KNO}$ on the deposition rate by sweeping the potential from $+0.6 \mathrm{~V}$ to $-0.7 \mathrm{~V}$.

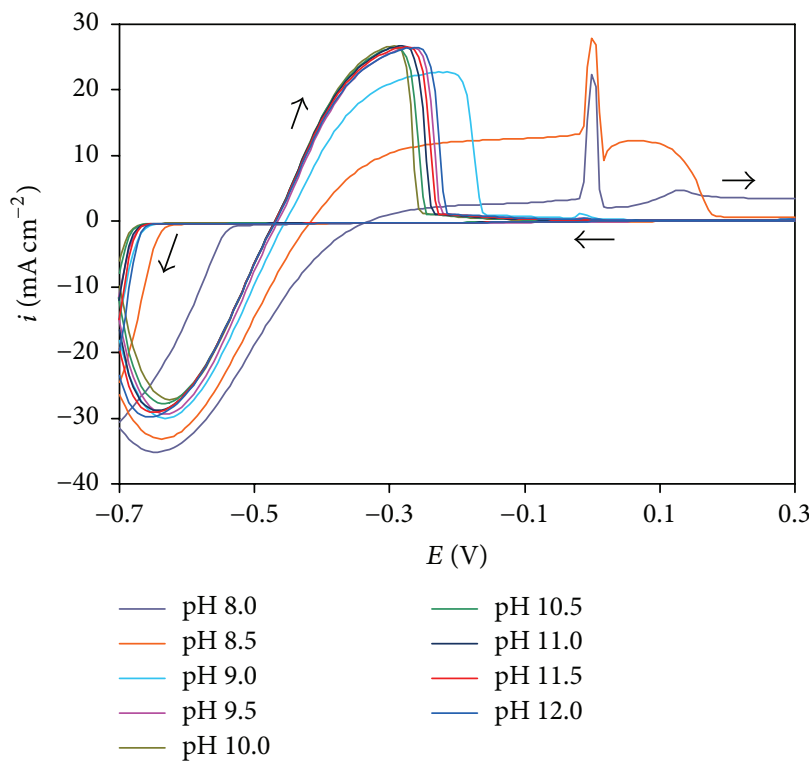

(a)

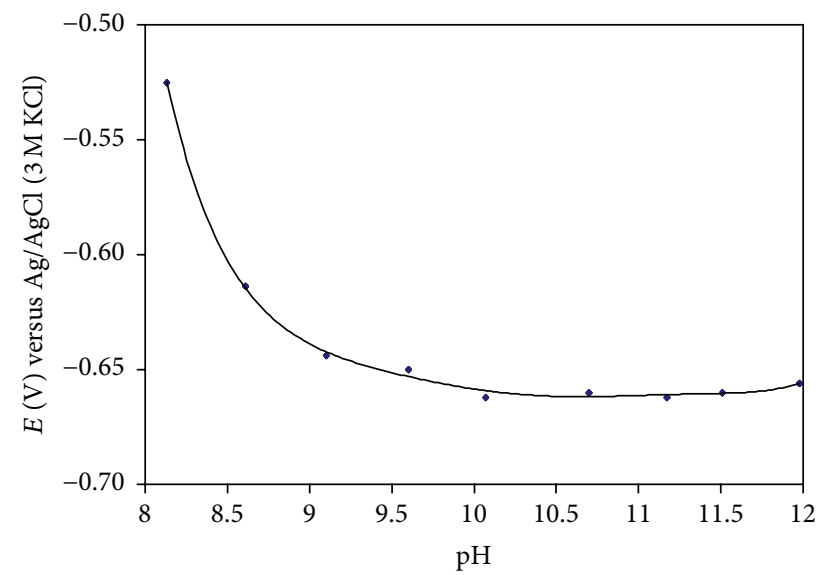

(b)

Figure 5: (a) Cyclic voltammograms showing the silver electrodeposition and silver film dissolution in the solutions consisting of $120 \mathrm{~g} / \mathrm{L}$ $\mathrm{KAg}(\mathrm{CN})_{2}, 6 \mathrm{~g} / \mathrm{L} \mathrm{KCN}$, and $120 \mathrm{~g} / \mathrm{L} \mathrm{KNO}_{3}$ at $\mathrm{pH}$ 8-12. (b) The effect of $\mathrm{pH}$ of the silver solutions on the onset potential of electrodeposition of silver ion on Pt electrode surface.

more $\mathrm{KNO}_{3}$ salt may help to reduce the operating current density required for silver electrodeposition at high silver concentration. Normally, the high current density approaching the diffusion limiting current is not recommended in industrial practice because of the inverse effects due to the depletion of silver ions in the double layer and the high possibility of causing hydrogen evolution, leading to rough and poor deposit [31].
3.5. The Effect of Bath pH on the Electrodeposition of Silver. Silver cyanide complexes are known to be unstable at very low $\mathrm{pH}$ because of the formation of insoluble $\mathrm{AgCN}$. This has imposed that the silver cyanide solution must be maintained in alkaline condition. Figures 5(a) and 5(b) show that increasing $\mathrm{pH}$ of the silver electrodeposition solution from 8.1 to 10 has shifted the onset of electrodeposition potential of silver to more negative direction and then the $\mathrm{pH}$ remains constant 
in the range of 10-12. $\mathrm{pH}$ less than 9.0 has a greater impact on the onset of silver electrodeposition potential.

The silver dissolution starts at around $-0.65 \mathrm{~V}$; there is one main dissolution peak, followed by a shoulder peak. At $\mathrm{pH}>9$, silver dissolution is dominated by the main peak around $-0.35 \mathrm{~V}$ while the shoulder peak is much smaller. On the other hand, the shoulder peaks around $1.0 \mathrm{mV}$ are considerably large when the solution $\mathrm{pH}$ is lower than 9.0. These peaks are positioned at the same potential with the oxidation peak of $\mathrm{KAg}(\mathrm{CN})_{2}$ solution as depicted in Figure 1(b). This suggested that, at $\mathrm{pH}<9$, the presence of $\left[\mathrm{Ag}(\mathrm{CN})_{2}\right]^{-}$is very pronounced at the platinum electrode.

Incomplete dissolution of silver at $\mathrm{pH} 8.1$ was observed when the anodic scan was swept until $+0.6 \mathrm{~V}$. The unusually long dissolution process in solution at $\mathrm{pH} 8.1$ suggests that the deposited silver is coarse and not homogeneous enough to fully cover the platinum electrode surface as the oxidation peak of $\left[\mathrm{Ag}(\mathrm{CN})_{2}\right]^{-}$ion is also observed. As a consequence, the optimum $\mathrm{pH}$ for the silver electrodeposition solution should be kept at $>9.5$ or favorably $10-12$ as, under this condition, the onset potential of silver electrodeposition remains quite constant and hence easier to control during the deposition process.

3.6. Effect of KCN on the Anodic Dissolution of Deposited Silver. The rate of anodic dissolution of metals strongly relies on the solution composition, particularly the type of anion and concentration [32]. For silver, its dissolution process involves free cyanide ions and depends on the cyanide concentration in the solution. The role of free cyanide in the dissolution of deposited silver can be described by (11) even though the dissolution process also involves the diffusion of free cyanide ions towards the silver surface, adsorption of cyanide ions, and formation of chemical bond with silver atom, as well as charge transfer $[33,34]$.

The dissolution of deposited silver in cyanide containing solutions is represented as follows:

$$
\mathrm{Ag}+2 \mathrm{CN}_{(b)}^{-} \longrightarrow \mathrm{Ag}(\mathrm{CN})_{2(b)}^{-}+\mathrm{e}^{-}
$$

When increasing the cathodic vertex potential to more negative values, the silver dissolution waves in the solution containing $6 \mathrm{~g} / \mathrm{L} \mathrm{KCN}$ seem to have reached the steadystate limiting current and cover a broad range of potentials (Figure 1(c)), whereas, in the solution containing $40 \mathrm{~g} / \mathrm{L} \mathrm{KCN}$, the silver dissolution peaks are sharper and the peak currents have also increased accordingly (Figure 6). This has indicated that the silver dissolution process consists of a limiting step and the reaction rate depends on the amount of free cyanide ions. It was reported that the dissolution of silver was limited by a stage of cyanide ions diffusion towards the electrode surface $[16,35]$. As a larger amount of free cyanide is available in high KCN containing solutions, the dissolution of deposited $\mathrm{Ag}$ is facilitated by the diffusion of free cyanide ions.

Figure 2(a) has also shown that, regardless of the amount of silver ions in the $6 \mathrm{~g} / \mathrm{L} \mathrm{KCN}$ solutions, the dissolution behavior is similar to those observed in low free cyanide containing solutions. The dissolution waves cover a very broad range of potentials which increases with increasing

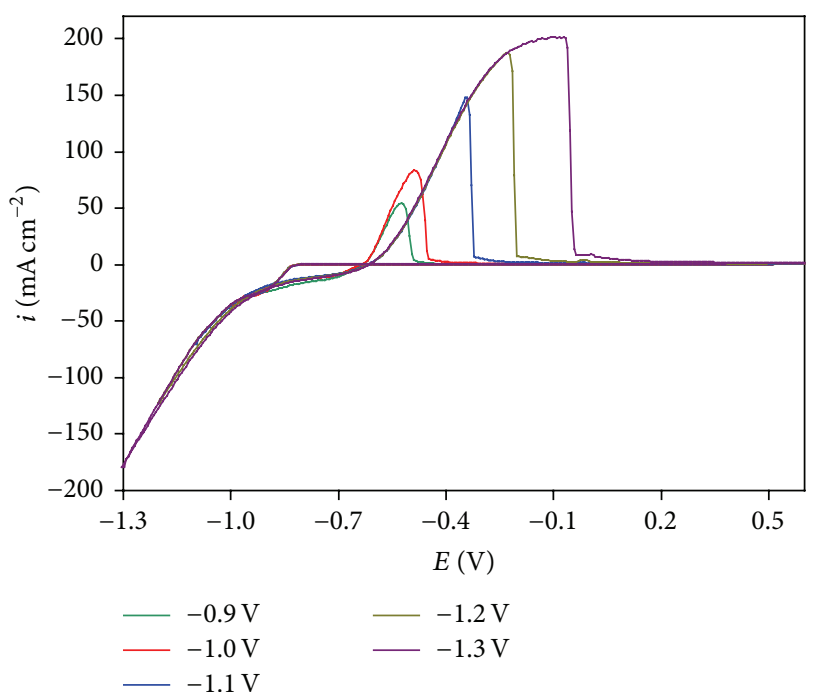

FIGURE 6: The current responses of dissolution of silver to different cathodic vertex potentials in the solution containing high potassium cyanide electrolyte. Electrolyte: $40 \mathrm{~g} / \mathrm{L} \mathrm{KCN}, 120 \mathrm{~g} / \mathrm{L} \mathrm{KAg}(\mathrm{CN})_{2}$, and $120 \mathrm{~g} / \mathrm{L} \mathrm{KNO}_{3}$. Initial potential: $+0.6 \mathrm{~V}$.

$\mathrm{KAg}(\mathrm{CN})_{2}$ concentration. The anodic current densities of silver remain at plateau before they drop rapidly. This also implies that increasing the $\mathrm{KAg}(\mathrm{CN})_{2}$ concentration does not help to increase the amount of free cyanide ions.

3.7. Characterization of the Plated Ag Films. The surface morphologies of Ag films electrodeposited by conventional high cyanide and the low cyanide silver solutions are shown in Figures 7(a)-7(b). It can be seen that there is no significant difference in the surface morphologies of the two Ag films. The surfaces of both Ag films appear to be quite smooth. Moreover, the AFM analysis has confirmed that the surface roughness $\left(R_{\mathrm{a}}\right)$ of both Ag films is comparable. $R_{\mathrm{a}}$ of Ag films electrodeposited by high cyanide and low cyanide systems are $8.8 \mathrm{~nm}$ and $9.8 \mathrm{~nm}$, respectively (Figures 7(c)-7(d)).

The XRD patterns in Figure 8 have also clearly shown that both Ag films are polycrystalline and exhibit (111), (200), (220), and (311) peaks. These four peaks are consistent with the published XRD diffraction result of Ag with purity $>99.999 \%$ (JCPDS, file number 04-0783) [36]. In addition, the crystallites of Ag film electrodeposited using low cyanide silver solution have the same preferred orientation in (111) plane as the film electrodeposited by using conventional high cyanide system.

The XPS depth profiles of the Ag films prepared from low cyanide and high cyanide solutions are also compared in Figure 9. Low cyanide Ag films have 100\% Ag after the depth of about $4 \mathrm{~nm}$ while high cyanide Ag films have 100\% $\mathrm{Ag}$ after $6 \mathrm{~nm}$. No other impurities are observed thereafter, showing high purity of both Ag films. Elements such as sulphur, oxygen, and carbon are also detected from the Ag surfaces. These contaminants are from the environment and are often adsorbed on sample surfaces. 

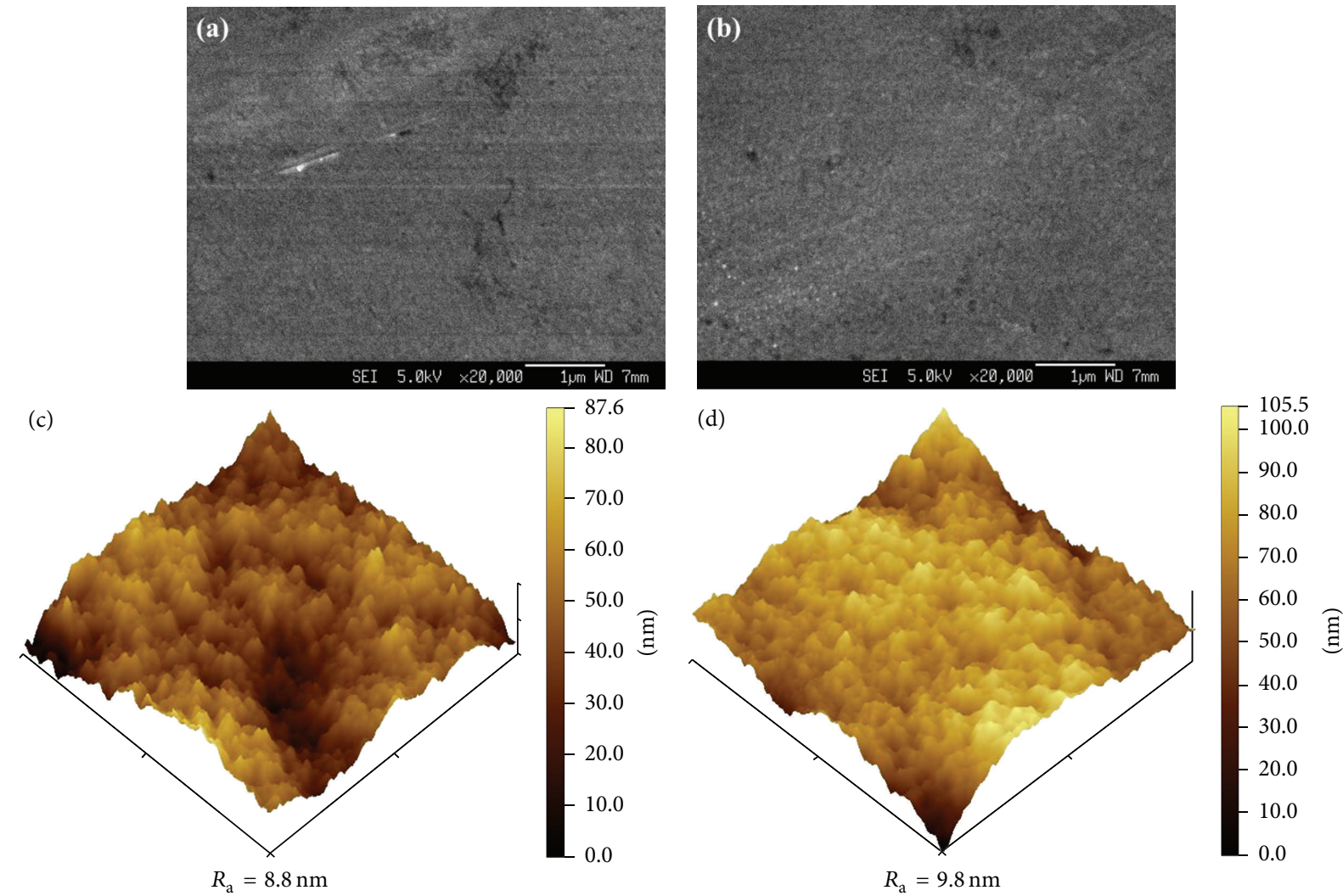

$R_{\mathrm{a}}=9.8 \mathrm{~nm}$

FIGURE 7: Scanning electron micrographs of Ag films electrodeposited by (a) high cyanide and (b) low cyanide silver solutions; the 3D AFM images and surface roughness $\left(R_{\mathrm{a}}\right)$ of Ag films electrodeposited by $(\mathrm{c})$ high cyanide and (d) low cyanide silver solutions.

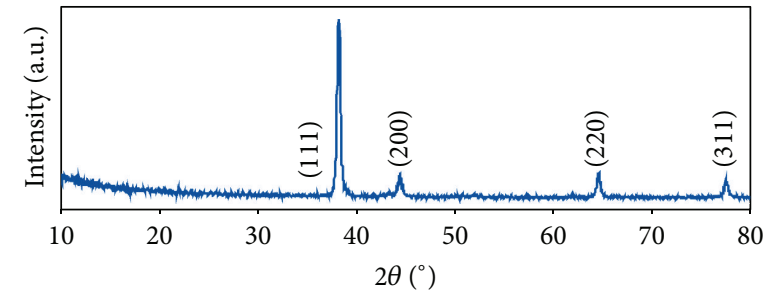

(a)

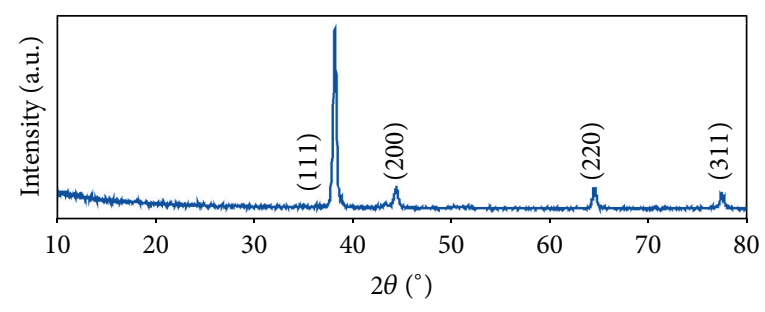

(b)

FIGURE 8: XRD patterns of Ag films electrodeposited by (a) high cyanide and (b) low cyanide silver solutions. The $y$-axes of all panels are presented in the same scale.

Under optimum conditions, the average reflectance $(R)$ of Ag films electrodeposited by both low cyanide and conventional high cyanide systems at $\lambda=450 \mathrm{~nm}$ is determined to be around $90-95 \%$. This shows that the brightness of the Ag films electrodeposited by low cyanide is comparable with the brightness of those electrodeposited by conventional high cyanide silver solution.

Besides that, both types of Ag films have comparable hardness in the range of about $100-120 \mathrm{Hv}_{0.05}$. On the other hand, the resistivity of $\mathrm{Ag}$ films electrodeposited by low cyanide and high cyanide solutions is found to be around $0.497 \pm 0.02 \mu \Omega \cdot \mathrm{cm}$ and $0.503 \pm 0.01 \mu \Omega \cdot \mathrm{cm}$, respectively.

\section{Conclusion}

The study shows the electrochemical behaviors of $\operatorname{KAg}(\mathrm{CN})_{2}$, $\mathrm{KCN}$, and $\mathrm{KNO}_{3}$ electrolytes and solutions $\mathrm{pH}$ on the silver electrodeposition and dissolution. Higher silver ion concentration shifts the onset potential of silver electrodeposition to more positive direction by lowering the electrode polarization while $\mathrm{KCN}$ has the opposite effect in changing the cathodic polarization. The onset potential of silver electrodeposition is shifted to more negative values with increasing KCN concentration. High plating speed or deposition rate can be attained in solutions containing high 


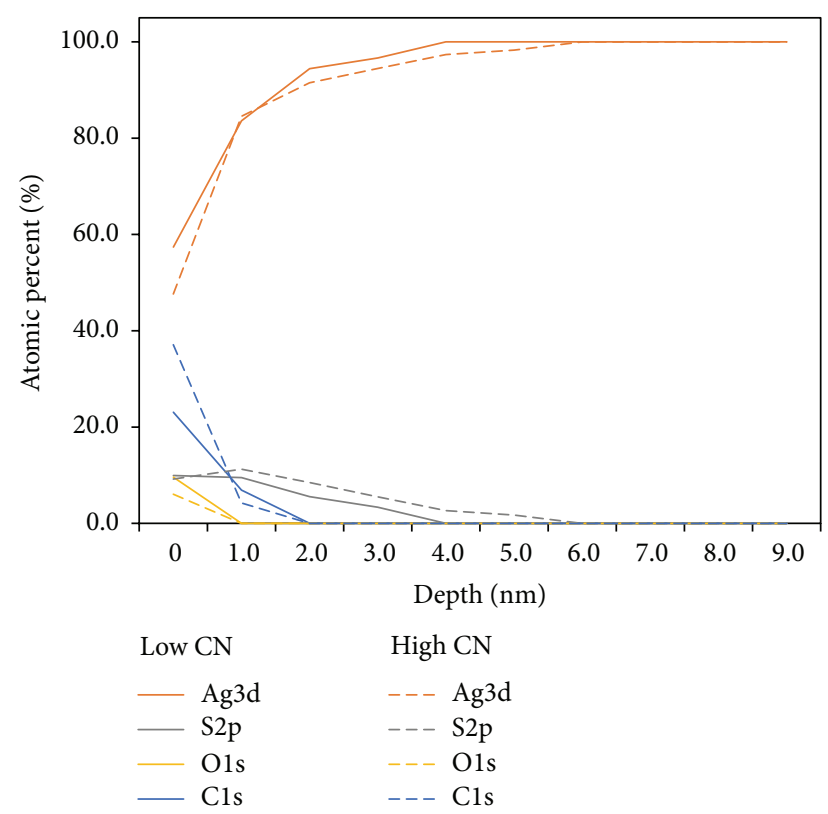

FIGURE 9: Compositional profile of Ag films prepared by low cyanide and high cyanide systems as a function of etched depth.

silver concentration. Besides having little impact on the onset potential of silver electrodeposition, $\mathrm{KNO}_{3}$ lowers the limiting current density as well as the electrodeposition rate. This implies that $\mathrm{KNO}_{3}$ may help reduce the operating current density required for silver electrodeposition in high silver concentration solutions, albeit at the expense of slowing down the electrodeposition rate. The silver plating solutions should be maintained at $\mathrm{pH}$ range $10-12$ as the onset potential of silver electrodeposition remains quite constant and hence easier to control during the operating process. The silver dissolution process consists of a limiting step and the reaction rate depended on the amount of free cyanide ions. The surface characteristics such as morphologies, purity, brightness, and conductivity, as well as hardness of $\mathrm{Ag}$ films electrodeposited by low cyanide system, are comparable with those electrodeposited by conventional high cyanide system. The XRD analysis and XPS depth profile have also shown very high purity of both types of Ag films.

\section{Competing Interests}

The authors declare that there are no competing interests regarding the publication of this paper.

\section{Acknowledgments}

The authors wish to thank MacDermid Enthone, Enthone Chemistry, for their equipment and financial support. They would also like to thank Mr. Swapan K. Biswas and Mr. Goh Min Hao for their technical advice and support.

\section{References}

[1] B. J. Polk, M. Bernard, J. J. Kasianowicz, M. Misakian, and M. Gaitan, "Microelectroplating silver on sharp edges toward the fabrication of solid-state nanopores," Journal of the Electrochemical Society, vol. 151, no. 9, pp. C559-C566, 2004.

[2] M. Miranda-Hernández and I. González, "Effect of potential on the early stages of nucleation and growth during silver electrocrystallization in ammonium medium on vitreous carbon," Journal of the Electrochemical Society, vol. 151, no. 3, pp. C220C228, 2004.

[3] B.-G. Xie, J.-J. Sun, Z.-B. Lin, and G.-N. Chen, "Electrodeposition of mirror-bright silver in cyanide-free bath containing uracil as complexing agent without a separate strike plating process," Journal of the Electrochemical Society, vol. 156, no. 3, pp. D79-D83, 2009.

[4] G. M. de Oliveira, M. R. Silva, and I. A. Carlos, "Voltammetric and chronoamperometric studies of silver electrodeposition from a bath containing HEDTA," Journal of Materials Science, vol. 42, no. 24, pp. 10164-10172, 2007.

[5] Z.-B. Lin, B.-G. Xie, J.-S. Chen, J.-J. Sun, and G.-N. Chen, "Nucleation mechanism of silver during electrodeposition on a glassy carbon electrode from a cyanide-free bath with 2-hydroxypyridine as a complexing agent," Journal of Electroanalytical Chemistry, vol. 633, no. 1, pp. 207-211, 2009.

[6] Z.-B. Lin, J.-H. Tian, B.-G. Xie et al., "Electrochemical and in Situ SERS studies on the adsorption of 2-hydroxypyridine and polyethyleneimine during silver electroplating," Journal of Physical Chemistry C, vol. 113, no. 21, pp. 9224-9229, 2009.

[7] R. Morrissey, "Non-cyanide silver plating bath composition," US Patent no. 20070151863 Al, 2007.

[8] M. Clauss and W. Zhang-Berlinger, "Cyanide-free silver electroplating solutions," United States Patent No. 8608932 B2, 2012.

[9] A. Liu, X. Ren, B. Wang et al., "Complexing agent study via computational chemistry for environmentally friendly silver electrodeposition and the application of a silver deposit," RSC Advances, vol. 4, no. 77, pp. 40930-40940, 2014.

[10] A. Liu, X. Ren, M. An et al., "A combined theoretical and experimental study for silver electroplating," Scientific Reports, vol. 4, article 3837, 2015.

[11] S. Jayakrishnan, S. R. Natarajan, and K. Vasu, "Alkaline noncyanide bath for electrodeposition of silver," Metal Finishing, vol. 94, no. 5, pp. 12-15, 1996.

[12] S. Sriveeraraghavan, R. M. Krishnan, and S. R. Natarajan, "Silver electrodeposition from thiosulfate solutions," Metal Finishing, vol. 87, pp. 115-117, 1989.

[13] N. Okamoto, F. Wang, and T. Watanabe, "Adhesion of electrodeposited copper, nickel and silver films on copper, nickel and silver substrates," Materials Transactions, vol. 45, no. 12, pp. 3330-3333, 2004.

[14] V. S. Bagotsky, "Reactions involving metals," in Fundamentals of Electrochemistry, pp. 297-317, John Wiley \& Sons, 2005.

[15] M. Schwartz, "Deposition from aqueous solutions: an overview," in Handbook of Deposition Technologies for Films and Coatings, R. F. Bunshah, Ed., p. 506, Noyes Publications, Park Ridge, NJ, USA, 1982.

[16] M. Schlesinger and M. Paunovic, Modern Electroplating, John Wiley \& Sons, 2011.

[17] S. K. Prasad, Advanced Wirebond Interconnection Technology, Springer Science \& Business Media, Berlin, Germany, 2004.

[18] H. Tamura, T. Arikado, H. Yoneyama, and Y. Matsuda, "Anodic oxidation of potassium cyanide on platinum electrode," Electrochimica Acta, vol. 19, no. 6, pp. 273-277, 1974.

[19] I. Krastev, A. Zielonka, S. Nakabayashi, and K. Inokuma, "A cyclic voltammetric study of ferrocyanide-thiocyanate silver 
electrodeposition electrolyte," Journal of Applied Electrochemistry, vol. 31, no. 9, pp. 1041-1047, 2001.

[20] V. F. C. Lins, M. M. R. Castro, C. R. Araújo, and D. B. Oliveira, "Effect of nickel and magnesium on zinc electrowinning using sulfate solutions," Brazilian Journal of Chemical Engineering, vol. 28, no. 3, pp. 475-482, 2011.

[21] S. Fletcher, "Some new formulae applicable to electrochemical nucleation/growth/collision," Electrochimica Acta, vol. 28, no. 7, pp. 917-923, 1983.

[22] Z. Zainal, S. Nagalingam, and T. M. Hua, "Properties of tin sulphide thin films electrodeposited in the presence of triethanolamine," Journal of Materials Science: Materials in Electronics, vol. 16, no. 5, pp. 281-285, 2005.

[23] A. M. Azzam and I. A. W. Shimi, "Studies of the properties of silver cyanide complexes," Zeitschrift für Anorganische und Allgemeine Chemie, vol. 321, no. 5-6, pp. 284-292, 1963.

[24] O. A. Ashiru and J. P. G. Farr, "Application of frequency response analysis to the determination of cathodic discharge mechanism during silver electroplating," Journal of the Electrochemical Society, vol. 142, no. 11, pp. 3729-3734, 1995.

[25] M. Fleischmann, G. Sundholm, and Z. Q. Tian, "An SERS study of silver electrodeposition from thiourea and cyanide containing solutions," Electrochimica Acta, vol. 31, no. 8, pp. 907-916, 1986.

[26] W. Vielstich and H. Gerischer, "Zur elektrolyse bei konstantem elektrodenpotential," Zeitschrift für Physikalische Chemie, vol. 3, no. 1-2, pp. 16-33, 1955.

[27] H. Sánchez, E. Chainet, B. Nguyen, P. Ozil, and Y. Meas, "Electrochemical deposition of silver from a low cyanide concentration bath," Journal of the Electrochemical Society, vol. 143, no. 9, pp. 2799-2815, 1996.

[28] G. Baltrunas, "The mechanism of electrode process in the system silver/silver cyanide complexes," Electrochimica Acta, vol. 48, no. 24, pp. 3659-3664, 2003.

[29] R. Morrissey, "Gold and silver plating basics: an overview of precious metal electroplating processes," Products Finishing, 2011.

[30] A. J. Bard and L. R. Faulkner, Electrochemical Methods, Student Solutions Manual: Fundamentals and Applications, John Wiley \& Sons, 2002.

[31] D. G. Foster, Y. Shapir, and J. Jorne, "The effect of rate of surface growth on roughness scaling," Journal of the Electrochemical Society, vol. 152, no. 7, pp. C462-C465, 2005.

[32] Y. M. Kolotyrkin, "Effect of specific adsorption of anions on hydrogen overvoltage," Transactions of the Faraday Society, vol. 55, pp. 455-462, 1959.

[33] G. Senanayake, "The cyanidation of silver metal: review of kinetics and reaction mechanism," Hydrometallurgy, vol. 81, no. 2, pp. 75-85, 2006.

[34] J. Li and M. E. Wadsworth, "Electrochemical study of silver dissolution in cyanide solutions," Journal of the Electrochemical Society, vol. 140, no. 7, pp. 1921-1927, 1993.

[35] J. B. Hiskey and V. M. Sanchez, "Mechanistic and kinetic aspects of silver dissolution in cyanide solutions," Journal of Applied Electrochemistry, vol. 20, no. 3, pp. 479-487, 1990.

[36] H. Swanson and E. Tatge, "Standard X-ray diffraction patterns," Journal of Research of the National Bureau of Standards, vol. 46, no. 4, p. 318, 1951. 

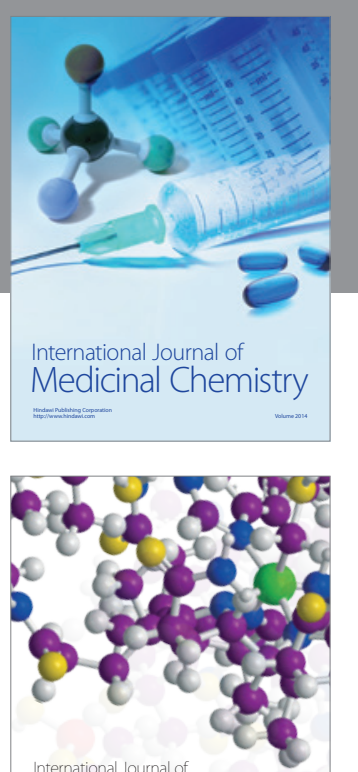

Carbohydrate Chemistry

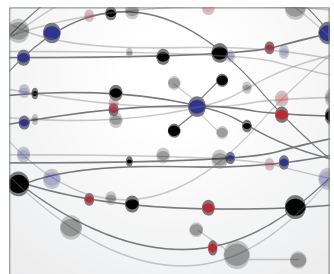

The Scientific World Journal
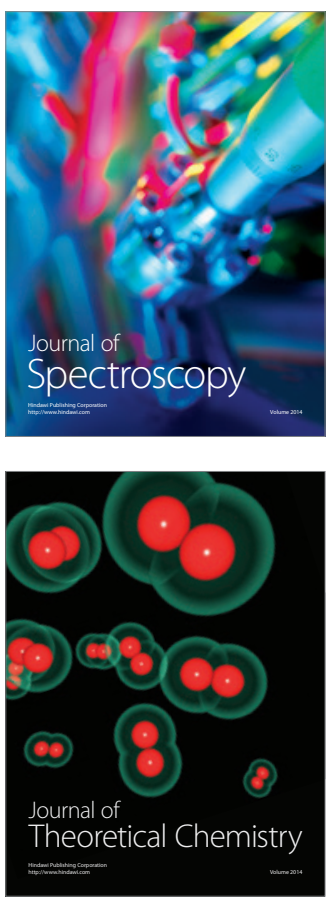
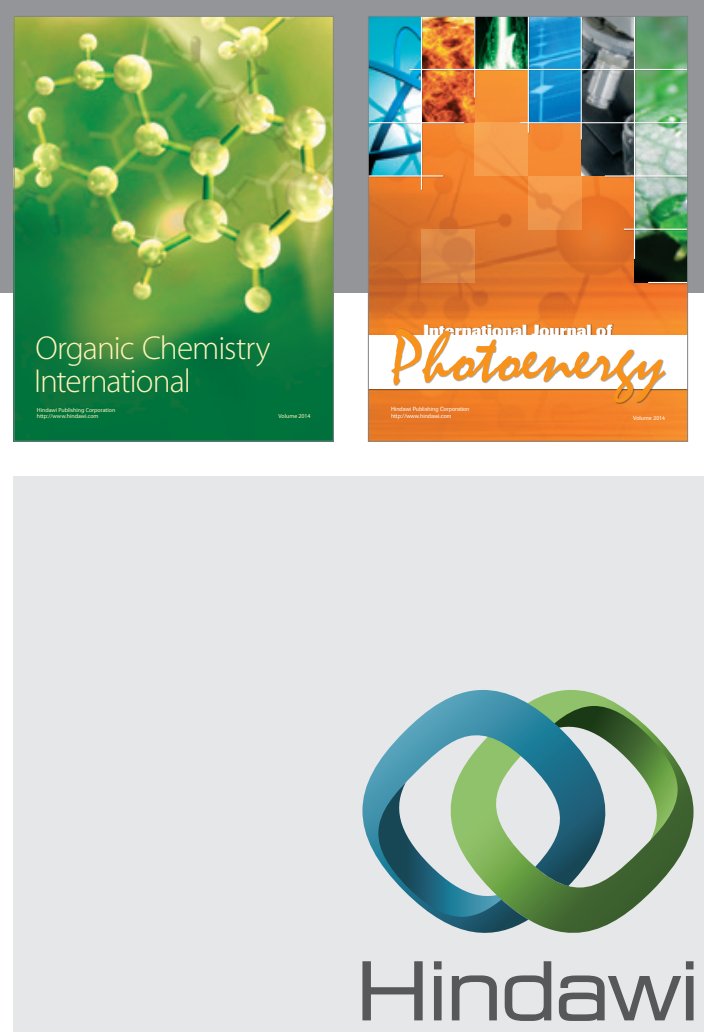

Submit your manuscripts at

http://www.hindawi.com

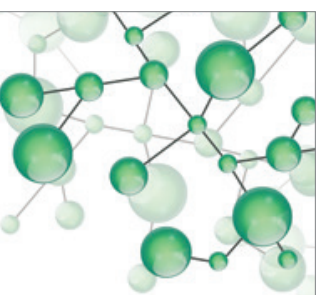

International Journal of

Inorganic Chemistry

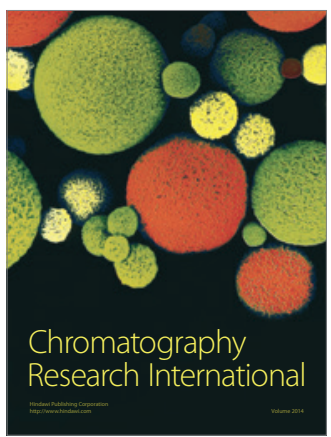

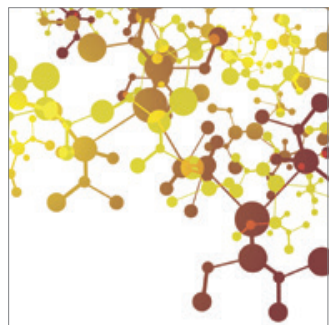

Applied Chemistry
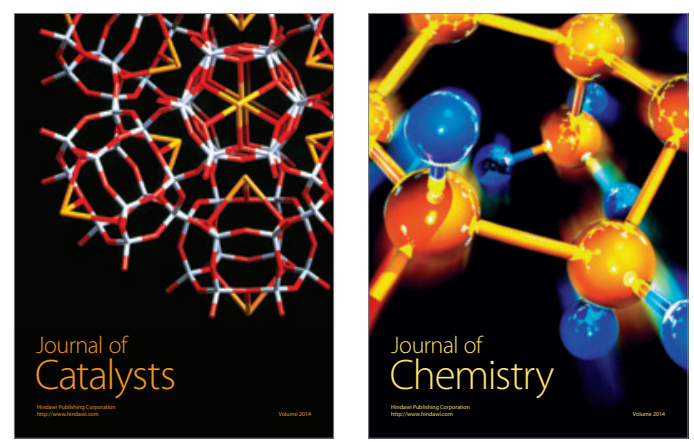
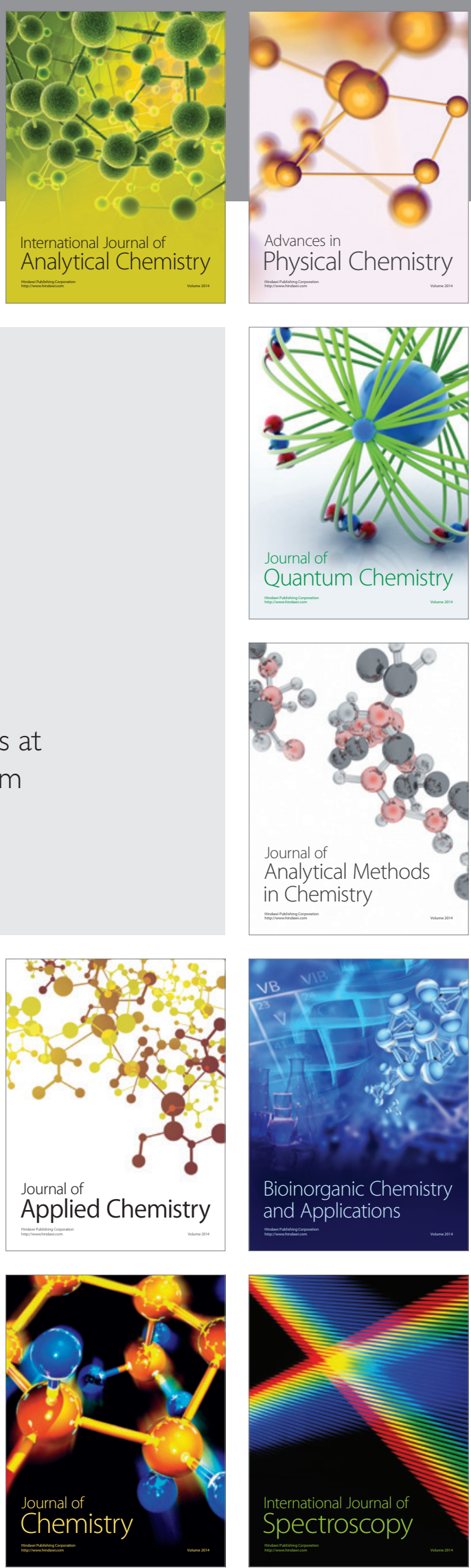